\title{
Evaluating methods for the isolation of marine-derived fungal strains and production of bioactive secondary metabolites
}

\author{
Miriam H. Kossuga, ${ }^{1}$ Stelamar Romminger, ${ }^{1}$ Camila Xavier, ${ }^{1}$ \\ Marília C. Milanetto, ${ }^{1}$ Milene Z. do Valle, ${ }^{1}$ Eli F. Pimenta, ${ }^{1}$ \\ Raquel P. Morais, ${ }^{1}$ Erica de Carvalho, ${ }^{1,2}$ Carolina M. Mizuno, ${ }^{1,2}$ \\ Luís Fernando C. Coradello, ${ }^{1,2}$ Vinícius de M. Barroso, ${ }^{1,2}$ Bruna \\ Vacondio, ${ }^{1,2}$ Darci C. D. Javaroti, ${ }^{2}$ Mirna H. R. Seleghim, ${ }^{2}$ \\ Bruno C. Cavalcanti, ${ }^{3}$ Claudia Pessoa, ${ }^{3}$ Manoel O. Moraes, ${ }^{3}$ \\ Bruna A. Lima, ${ }^{4}$ Reginaldo Gonçalves, ${ }^{4}$ Rafaella C. Bonugli- \\ Santos, ${ }^{5}$ Lara D. Sette, ${ }^{5}$ Roberto G. S. Berlinck ${ }^{*}, 1$
}

${ }^{1}$ Instituto de Química de São Carlos, Universidade de São Paulo, Brazil, ${ }^{2}$ Departamento de Ecologia e Biologia Evolutiva, Universidade Federal de São Carlos, Brazil,

${ }^{3}$ Departamento de Fisiologia e Farmacologia, Universidade Federal do Ceará, Brazil,

${ }^{4}$ Departamento de Diagnóstico Oral, Faculdade de Odontologia de Piracicaba, Universidade Estadual de Campinas, Brazil,

${ }^{5}$ Departamento de Bioquimica e Microbiologia, Universidade Estadual Paulista, Rio Claro, Brazil.

\begin{abstract}
In the present investigation we evaluate methods for the isolation and growth of marine-derived fungal strains in artificial media for the production of secondary metabolites. Inoculation of marine macroorganisms fragments in Petri dishes proved to be the most convenient procedure for the isolation of the largest number of strains. Among the growth media used, 3\% malt extract showed the best result for strains isolation and growth, and yielded the largest number of strains from marine macroorganisms. The percentage of strains isolated using each of the growth media which yielded cytotoxic and/or antibiotic extracts was in the range of $23-35 \%$, regardless of the growth media used. Further investigation of extracts obtained from different marine-derived fungal strains yielded several bioactive secondary metabolites, among which $(E)$-4-methoxy-5-(3-methoxybut-1-enyl)-6methyl-2H-pyran-2-one is a new metabolite isolated from the Penicillium paxilli strain $\mathrm{Ma}(\mathrm{G}) \mathrm{K}$.
\end{abstract}

Revista Brasileira de Farmacognosia Brazilian Journal of Pharmacognosy 22(2): 257-267, Mar./Apr. 2012

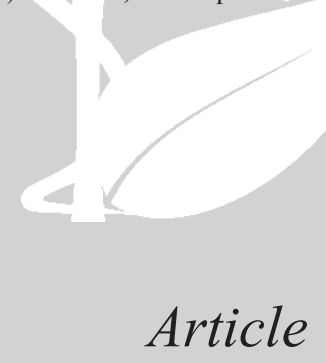

Received 26 May 2011

Accepted 18 Aug 2011

Available online 5 Dec 2011

Keywords:

antimicrobial

biological screening cytotoxic

marine-derived fungi
ISSN 0102-695X http://dx.doi.org/10.1590/S0102$695 \times 2011005000222$

\section{Introduction}

Since the early 1990's the oceans have been recognized as one of the latest untapped environments of unknown microorganisms. Up to then, the occurrence of true marine strains of bacteria and fungi has been only occasionally reported. With the advent of molecular biology tools, it has been possible to isolate and identify obligate marine bacteria and fungi present in the oceans. Continuous investigations demonstrated that marine microorganisms are an unlimited source of novel biologically active secondary metabolites (Fenical, 1993; Gallagher et al., 2010; Hughes \& Fenical, 2010; Jensen \& Fenical, 1994; Kelecom, 2002; Newman \& Hill, 2006).

Marine-derived fungi, in particular, have yielded an increasing number of biologically active natural products (Bugni \& Ireland, 2004; Saleem et al., 2007; Rateb \& Ebel, 2011). While the majority of compounds isolated from marine-derived fungal strains are polyketidederived, alkaloids, terpenes, peptides and compounds of mixed biosynthesis are also representative groups of secondary metabolites produced by these fungi. The chemical diversity of the marine-derived fungi secondary metabolism, along with the strains novelty, points this group of microorganisms as of much interest for the isolation of unusual bioactive natural products.

We have already started the first research program in Brazil aiming at the isolation of bioactive natural products from marine-derived microorganisms. A number of new compounds have been previously reported by us 
(Hernandez et al., 2000; Hernandez et al., 2004; Lira et al., 2006; Pimenta et al., 2010). We have subsequently developed a multi-screening approach in order to obtain and select bioactive extracts from marine-derived fungi culture media (Vita-Marques et al., 2008). While a number of active extracts producing strains have been detected, such extracts have been obtained in only very limited amounts. Hampered by such circumstances, we envisaged a culture media screening aiming to improve the isolation of fungal strains which provide bioactive extracts, as well as the amount of extracts produced by such marinederived fungi. Herein we report the results of this screening approach that enabled us to obtain several natural products in sufficient quantities for the evaluation of their biological activities.

\section{Material and Methods}

\section{Fungal strains identification}

Fungal isolates were identified by conventional and molecular approaches. Fungal macromorphology was examined by colony observation with a stereomicroscope (Leica MZ6, Wetzlar, Germany) and micromorphology analysis using a light microscope (Leica DM LS, Wetzlar, Germany) by wet mounts stained with Cotton Blue. Molecular identification was carried out by sequencing the 28S rDNA (D1/D2 region) and/or ITS1-5.8S-ITS2 rDNA regions coupled with phylogenetic analyses as described in Menezes et al. (2010). Identification sequences for each fungal strain which was identified can be requested to Dr. Lara Sette (larasette@rc.unesp.br). Samples of macroorganisms and marine-derived
filamentous fungi

Samples of marine invertebrates and of an alga were collected at Toque-Toque Island, off São Paulo state north coastline, Brazil: three samples of ascidians, a white Didemnum species, Didemnum granulatum (Didemnidae, Tokioka, 1954) and Didemnum ligulum (Didemnidae, Monniot, 1983); four samples of marine sponges, Axinella cf. corrugata (Axinellidae, George \& Wilson, 1919), Dragmacidon reticulatum (Axinellidae, Ridley \& Dendy, 1886), Geodia corticostylifera (Astrophorida, Hajdu, Muricy, Custodio, Russo \& Peixinho, 1992) and Mycale angulosa (Mycalidae, Duchassaing \& Michelotti, 1864) and one marine alga, Sargassum sp. Vouchers of these species are deposited at Museu Nacional, Universidade Federal do Rio de Janeiro (sponges), at Departamento de Zoologia, Setor de Ciências Biológicas, Universidade Federal do Paraná (ascidians) and at CEBIMar (Sargassum sp.). All samples were collected in sterilized plastic bags and immediately transported to the Universidade de São Paulo Marine Station, CEBIMar. Marine sponges and alga have been identified by Dr. Marcio R. Custódio, while ascidians have been identified by Dr. Rosana M. Rocha. In the laboratory, the animals and the alga were cleaned from visible debris and subsequently washed with a solution of $\mathrm{HgCl}_{2}$ in $\mathrm{EtOH}(1 \mathrm{mg} / \mathrm{mL})$ during $1 \mathrm{~min}$, followed by three washes with sterilized sea water (Newel, 1976).

After surface sterilization, fragments of approx. 1 $\mathrm{cm}^{3}$ from the inner part of each macroorganism specimen were inoculated on Petri dishes using three different procedures: a) spreading the fragments on different recipes of agar plates media; b) placing the fragments, without spreading, on agar plates containing the same media recipes; c) inoculation of homogenized fragments in agar plates with the same growth media. Homogenized fragments were placed in test tubes with $10 \mathrm{~mL}$ of sterilized sea water and homogenized using a sterile Ultra-Turrax ${ }^{\circledR}$. Serial dilutions were obtained to $10^{-2}$ and $100 \mu \mathrm{L}$ of each dilution was inoculated. Media used in Petri dishes are provided below. Growth in Petri dishes were performed at $25{ }^{\circ} \mathrm{C}$.

All fungi growth media ( $\mathrm{pH}$ 8.0) were prepared using artificial sea water (ASW: Vita-Marques et al., 2008): artificial sea water agar (ASW: 1 L of ASW; agar $15 \mathrm{~g}$ ), glucose peptone yeast (GPY: glucose $1 \mathrm{~g}$; soybean meat peptone $0.5 \mathrm{~g}$; yeast extract $0.1 \mathrm{~g}$; ASW 1L; agar 15 g), $2 \%$ malt $(2 \% \mathrm{M}$ : malt extract $20 \mathrm{~g}$; ASW $1 \mathrm{~L}$; agar 15 g); $3 \%$ malt (3\%M: malt extract $30 \mathrm{~g}$; mycological peptone 5 g; ASW 1 L; agar 15 g), Tubaki (TUB: glucose 30 g; yeast extract $1 \mathrm{~g}$; peptone $1 \mathrm{~g} ; \mathrm{K}_{2} \mathrm{HPO}_{4} 1 \mathrm{~g} ; \mathrm{MgSO}_{4} 0.5$ g; $\mathrm{FeSO}_{4} 0.01 \mathrm{~g}$, ASW 1L pH 8.0; agar $15 \mathrm{~g}$ ), potatocarrot medium (PCM: Potatoes cooked and smashed 20 g; carrots cooked and smashed 20g; ASW $1 \mathrm{~L}$; agar $20 \mathrm{~g}$ ); corn meal medium (CMM: $42 \mathrm{~g}$ of corn flour were stirred overnight in $500 \mathrm{~mL}$ of distilled $\mathrm{H} 2 \mathrm{O}$ at $60^{\circ} \mathrm{C}$, filtered and the filtered medium was diluted to $1 \mathrm{~L}$ with ASW; agar 15 $\mathrm{g}$ ), oat meal medium (OMM: $30 \mathrm{~g}$ of oat flakes were boiled in $500 \mathrm{~mL}$ of distilled $\mathrm{H}_{2} \mathrm{O}$ during one hour, filtrated and the filtered medium was diluted to $1 \mathrm{~L}$ with ASW; agar $20 \mathrm{~g}$ ) and cellulose medium (CELM: cellulose $10 \mathrm{~g}$, yeast extract $1 \mathrm{~g} ; 1 \mathrm{~L}$ ASW; agar $15 \mathrm{~g})$. Rifampicin was added in all media used for inoculation at a concentration of 300 $\mathrm{mg} / \mathrm{L}$ in order to prevent bacterial contamination.

After inoculation, plates were regularly examined in order to verify the growth of filamentous fungi. Isolation of strains was performed as previously reported (VitaMarques et al., 2008). Pure fungal colonies obtained by successive purification steps were photographed, morphologically described, subjected to microscopic analysis and deposited at the Microbiology Laboratory, Departamento de Ecologia e Biologia Evolutiva, Universidade Federal de São Carlos. Fungal strains have been preserved using three distinct procedures: a) in distilled water stored at $4{ }^{\circ} \mathrm{C}$ (Deshmukh, 2003); b) in glycerol $10 \%$ stored at $-18{ }^{\circ} \mathrm{C}$ (Deshmukh, 2003) and c) in microbiological tubes containing agar slants, maintained at 
$2-4{ }^{\circ} \mathrm{C}$, periodically transferred each three months. Media used for preservation were respectively the same used for strains isolation and growth.

\section{Small scale fungi cultivation}

All fungal samples were firstly grown in Petri dishes using the same media employed for isolation. After growth, $2 \mathrm{~mm}$ surface circles of mycelia were obtained using sterilized Pasteur pipettes and inoculated in $250 \mathrm{~mL}$ of culture broth of identical media formulation in which each strain was isolated. Cultures were cultivated at 25 ${ }^{\circ} \mathrm{C}$, in still mode. The time of incubation varied according the each strain growth rate. Rapidly growing strains were incubated during seven days, while slowly growing strains were incubated up to 28 days.

\section{Crude extracts from culture media}

After growth in liquid media, fungal cultures were processed as follows. The media of strains grown in clarified media (GPY, 2\%M, 3\%M and TUB) were filtered through a Celite bed under vacuum. The mycelia of each culture were extracted with $\mathrm{MeOH}$ during $1 \mathrm{~min}$ in an ultrasonic bath and filtered. The filtered liquid media were adsorbed onto $\mathrm{C}_{18}$ reversed-phase cartridges. The columns were washed with $100 \% \mathrm{H}_{2} \mathrm{O}$, and this fraction was discarded in order to eliminate salts and media nutrients.

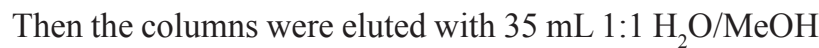

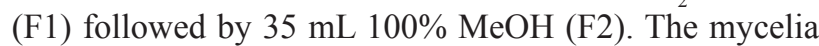
$\mathrm{MeOH}$ extracts (MyE) and the two fractions (F1 and F2) obtained from the solid-phase extraction were evaporated to dryness in vacuo ( speedvac $^{\circledR}$ ).

Strains grown in non-clarified media (PCM, CMM, OMM, CELM) yielded crude extracts obtained as follows. EtOAc $(250 \mathrm{~mL})$ was added to each flask containing the growth media+mycelia. The mixture was blended and left in a shaker (200 rpm) overnight, filtered through a Celite bed under vacuum and transferred to a separatory funnel. The EtOAc was collected, evaporated in vacuo, transferred to labeled vials with $\mathrm{MeOH}$ and evaporated to dryness in vacuo ( speedvac $^{\circledR}$ ).

\section{Antimicrobial and cytotoxic assays of crude extracts}

Procedures for antimicrobial and cytotoxic assays have been previously reported in Kossuga et al. (2009) and in Seleghim et al. (2007), respectively.

\section{HPLC-UV-MS analyses}

HPLC-UV-MS analyses were performed using a Waters Alliance 2695 coupled on-line with a Waters 2996 photodiode array detector, followed by a Micromass ZQ2000 MS detector with an electrospray interface. The photodiode array scanned the samples at $\lambda_{\max } 200-400$ $\mathrm{nm}$. The MS detector was optimized to the following conditions-capillary voltage: $3.00 \mathrm{kV}$, source block temperature: $100{ }^{\circ} \mathrm{C}$, desolvation temperature: $350{ }^{\circ} \mathrm{C}$, operating in electrospray positive mode, detection range: 200-800 Da with total ion count extracting acquisition. The cone and desolvation gas flow were 50 and $350 \mathrm{~L} / \mathrm{h}$, respectively, and were obtained from a Nitrogen Peak Scientific N110DR nitrogen source. Data acquisition and processing were performed using Empower 2.0.

One mg of each sample was diluted in appropriate vials containing $\mathrm{MeOH}(1 \mathrm{~mL})$. Analyses were performed using a $\mathrm{C}_{18}$ reversed-phase Inertsil ${ }^{\circledR}$ column $(4.6 \times 250 \mathrm{~mm}$, $5 \mu \mathrm{m}$ ), using a gradient of $1: 1 \mathrm{MeCN} / \mathrm{MeOH}$ in $\mathrm{H}_{2} \mathrm{O}+0.1 \%$ formic acid at $1 \mathrm{~mL} / \mathrm{min}$, starting at $10 \%$ organic eluent and ended at $100 \%$ organic eluent after $40 \mathrm{~min}$.

\section{Isolation of secondary metabolites from the culture media} of selected fungal strains

Strain AC(M2)14A, isolated from the sponge Axinella cf. corrugata and identified as Penicilium raistrickii, was inoculated in four $500 \mathrm{~mL}$ Erlenmeyer flasks containing $250 \mathrm{~mL}$ of $2 \%$ malt extract medium each. The strain was grown in static mode during 14 days at $25{ }^{\circ} \mathrm{C}$. After growth, the culture medium was filtered over Celite. The filtered culture medium was adsorbed onto a $\mathrm{C}_{18}$ reversed-phase column cartridge (10 g), which was washed with $\mathrm{H}_{2} \mathrm{O}(25 \mathrm{~mL})$, then eluted with $1: 1 \mathrm{H}_{2} \mathrm{O} /$ $\mathrm{MeOH}(25 \mathrm{~mL})$ and $100 \% \mathrm{MeOH}(25 \mathrm{~mL})$. HPLC/UV/MS analysis of the $\mathrm{MeOH}$ fraction indicated a major peak with $\lambda_{\text {max }} 240$ and $310 \mathrm{~nm}$ in the UV spectrum and a peak with $\mathrm{m} / \mathrm{z} 259$ in the mass spectrum, corresponding to the $[\mathrm{M}+\mathrm{H}]^{+}$ ion of 1. HPLC purification (column: Inertsil Phenyl, 4.6 x $250 \mathrm{~mm}, 5 \mu \mathrm{m}, 150 \AA$; eluent: $7: 3 \mathrm{MeOH} / \mathrm{H}_{2} \mathrm{O}$ ) of the major compound led to the isolation of 1,3,6-trihydroxy8-methyl-9H-xanthen-9-one, or norliquexanthone (1), the identity of which was established based on comparison of its spectral properties with published data (Sundholm, 1978).

Strain AS(F)39, isolated from the alga of the genus Sargassum and identified as $P$. steckii, was inoculated in a $500 \mathrm{~mL}$ Schott flask containing $250 \mathrm{~mL}$ of corn meal broth. The strain was grown in still mode during 28 days at $25{ }^{\circ} \mathrm{C}$. After growth, $250 \mathrm{~mL}$ of EtOAc was added and the mixture was shaken overnight before filtration over Celite and subsequent liquid-liquid partition. The organic phase was evaporated to dryness, to give $57 \mathrm{mg}$ of a crude extract which displayed antibiotic activity against Candida albicans ATCC36801 and Streptoccocus mutans UA159 and presented a ${ }^{1} \mathrm{H}$ NMR spectrum of a single aromatic compound contaminated with fatty acids. HPLC purification of this crude extract (column: $\mathrm{C}_{18}$ Inertsil ODS-3, 4.6 x $250 \mathrm{~mm}, 5 \mu \mathrm{m}$; eluent: 75:25 MeOH/ $\mathrm{H}_{2} \mathrm{O}$; flow: $1 \mathrm{~mL} / \mathrm{min}$ ) led to the isolation of $(S)-8$-methoxy-3,5- 
dimethylisochroman-6-ol (2) (Lai et al., 1990; Masuma et al., 1994; He et al., 2004; Kerti et al., 2007). The comparison of ${ }^{1} \mathrm{H},{ }^{13} \mathrm{C}$ NMR and MS data of 2 with literature values (Masuma et al., 1994; Cox et al., 1979) did not allow us to distinguish it from 6-methoxy-3,7-dimethylisochroman8-ol (3) (Cox et al., 1979). Therefore, compound 2 was identified by analysis of COSY, HSQC and HMBC NMR spectra. The absolute configuration of $\mathbf{2}$ was established by comparison of its $[\alpha] \mathrm{D}^{25}+142(c 0.1, \mathrm{MeOH})$ with the literature values (Lai et al., 1990; Masuma et al., 1994; He et al., 2004; Kerti et al., 2007).

Strain DG(M3)6'C, isolated from the ascidian Didemnum granulatum and identified as Penicillium sp., was inoculated in two $500 \mathrm{~mL}$ Schott flasks containing $250 \mathrm{~mL}$ of $3 \%$ malt broth each. The strain was grown in static mode during 14 days at $25^{\circ} \mathrm{C}$. After growth, $250 \mathrm{~mL}$ of EtOAc was added to each Erlenmmeyer, the mixture was blended and left shaking overnight before filtration over Celite and subsequent liquid-liquid partitioning. The organic phase was evaporated to dryness, to give a cytotoxic crude extract. The whole EtOAc extract was subjected to a solid-phase extraction on a $\mathrm{C}_{18}$ reversed-phase cartridge (10 g), using 100\% $\mathrm{H}_{2} \mathrm{O}, 1: 1 \mathrm{H}_{2} \mathrm{O} / \mathrm{MeOH}$ and $100 \% \mathrm{MeOH}$ as eluents. The $1: 1 \mathrm{H}_{2} \mathrm{O} / \mathrm{MeOH}$ and $100 \% \mathrm{MeOH}$ fractions were pooled, evaporated to dryness to give $25.7 \mathrm{mg}$. This fraction was purified by HPLC, using a Waters DeltaPak column $(300 \times 7.8 \mathrm{~mm}, 15 \mu \mathrm{m}, 100 \AA)$ using 37.5/37.5/25 $\mathrm{MeOH} / \mathrm{MeCN} / \mathrm{H}_{2} \mathrm{O}$ as eluent $+0.1 \%$ of trifluoroacetic acid, at a flow rate of $2.0 \mathrm{~mL} / \mathrm{min}$. The purification yielded 2.2 $\mathrm{mg}$ of a single major metabolite, identified as 13-desoxyphomenone (4), identified by analysis of spectroscopic data (UV, MS, ${ }^{1} \mathrm{H},{ }^{13} \mathrm{C}$, COSY, HSQC and HMBC NMR data) and comparison with literature data (Tirilly et al., 1983).

Strain $\mathrm{Ma}(\mathrm{T}) \mathrm{H}$, isolated from the sponge $M$. angulosa and identified as Trichoderma sp., was inoculated in one $500 \mathrm{~mL}$ Schott flask containing $250 \mathrm{~mL}$ of Tubaki medium. The strain was grown in static mode during 28 days. After growth, the culture medium was filtered over Celite. The filtered culture medium was adsorbed into a $\mathrm{C}_{18}$ reversed-phase cartridge (10 $\left.\mathrm{g}\right)$, which was washed with $\mathrm{H}_{2} \mathrm{O}(25 \mathrm{~mL})$, then eluted with $1: 1 \mathrm{H}_{2} \mathrm{O} / \mathrm{MeOH}(25$ $\mathrm{mL})$ and $100 \% \mathrm{MeOH}(25 \mathrm{~mL})$. The $1: 1 \mathrm{H}_{2} \mathrm{O} / \mathrm{MeOH}$ fraction $(11.5 \mathrm{mg})$ displayed cytotoxic activity against colon, breast and human leukemia cancer cell lines. This fraction was separated by HPLC, using a $\mathrm{C}_{18}$ reversedphase Phenomenex column $(4.6 \times 250 \mathrm{~mm}, 4 \mu \mathrm{m})$, using $1: 1 \mathrm{H}_{2} \mathrm{O} / \mathrm{MeOH}$ as eluent. Five fractions were obtained, of which Ma(T)HF2-P3 (0.6 mg), Ma(T)HF2-P4 (1.9 $\mathrm{mg})$ and $\mathrm{Ma}(\mathrm{T}) \mathrm{HF} 2-\mathrm{P} 5(0.1 \mathrm{mg})$ were considered as pure metabolites, related to tricothecenes. However, only the structure of compound Ma(T)HF2-P4 could be established as roridin A (5) by analysis of its spectroscopic data (Steinmetz et al., 2008). Only the relative configuration of 5 has been established by us.
Strain $\mathrm{Ma}(\mathrm{G}) \mathrm{K}$, also obtained from the sponge $M$. angulosa and identified as $P$. paxilli, was inoculated in ten $500 \mathrm{~mL}$ Schott flasks containing $200 \mathrm{~mL}$ of $2 \% \mathrm{M}$ medium each, in a rotator shaker $(100 \mathrm{rpm})$ at $25^{\circ} \mathrm{C}$ during seven days. Then, $200 \mathrm{~mL}$ of EtOAc was added to each Schott flask, and left shaking at $100 \mathrm{rpm}$ during $24 \mathrm{~h}$ at $25^{\circ} \mathrm{C}$. The mixture of the culture media and EtOAc was filtered through a Celite bed and the organic phase was separated by liquid-liquid partitioning. After evaporation, the EtOAc extract $(400 \mathrm{mg})$ was separated by chromatography on a cyanopropyl-bonded sílica-gel cartridge (2 g), eluted first with $100 \% \mathrm{CH}_{2} \mathrm{Cl}_{2}$ (fraction $\mathrm{Ma}(\mathrm{G}) \mathrm{K}-\mathrm{A}, 130.0 \mathrm{mg}$ ), then $100 \%$ EtOAc (fraction $\mathrm{Ma}(\mathrm{G}) \mathrm{K}-\mathrm{B}, 68.2 \mathrm{mg}$ ) then $100 \% \mathrm{MeOH}$ (fraction $\mathrm{Ma}(\mathrm{G}) \mathrm{K}-\mathrm{C}, 155.0 \mathrm{mg}$ ). Analysis by $\mathrm{LC} / \mathrm{UV} / \mathrm{MS}$ indicated the presence of peaks with UV absorptions at 220-230 and 280-300 nm, in the mass range between 240 and $260 \mathrm{Da}$ in fraction $\mathrm{Ma}(\mathrm{G}) \mathrm{K}-\mathrm{A}$. This fraction was separated by HPLC using a $\mathrm{C}_{18}$ reversedphase column Inertsil ODS-3 $(4.6 \times 250 \mathrm{~mm} ; 5 \mu \mathrm{m})$ and a gradient of $1: 1 \mathrm{MeOH} / \mathrm{MeCN}$ in $\mathrm{H}_{2} \mathrm{O}+0,1 \%$ formic acid, with a $1.0 \mathrm{~mL} / \mathrm{min}$ flow rate and monitoring at $\lambda=254 \mathrm{~nm}$. This separation yielded $6.0 \mathrm{mg}$ of 5-(3-hydroxybutanoyl)4-methoxy-6-methyl-2H-pyran-2-one (pyrenocine B, 6), $42.7 \mathrm{mg}$ of (E)-5-but-2-enoyl-4-methoxy-6-methyl$2 \mathrm{H}$-pyran-2-one (pyrenocine $\mathrm{A}, 7)$ and $0.8 \mathrm{mg}$ of $(E)-4-$ methoxy-5-(3-methoxybut-1-enyl)-6-methyl-2H-pyran2-one (8), representing a new natural product for which the name pyrenocine $\mathbf{J}$ is suggested. All compounds were identified by analysis of spectroscopic data and comparison with literature data.

Pyrenocine $J$ (8): yellowish white amorphous solid. UV $\lambda_{\max }$ nm (c.) MeOH: 228 (49012), 285 (14646). FT-IR $\left(\mathrm{cm}^{-1}\right): 2926,1709,1558,1251 .{ }^{1} \mathrm{H}$ NMR (400 MHz, TMS, DMSO- $\left.d_{6}\right): \delta(\mathrm{ppm}) ; 1.20(3 \mathrm{H}, \mathrm{d}, J=6.3 \mathrm{~Hz}$, H3-10), 2.28 (3H, s, H3-12), 3.20 (3H, s, H3-13), 3.83 (overlapping m, H3-11, H-9), $5.61(1 \mathrm{H}, \mathrm{s}, \mathrm{H}-3), 5.81(1 \mathrm{H}$, $\mathrm{dd}, J=7.2$ and $16.0 \mathrm{~Hz}, \mathrm{H}-8), 6.20(1 \mathrm{H}, \mathrm{d}, J=16.0 \mathrm{~Hz}, \mathrm{H}-7)$. ${ }^{13} \mathrm{C}$ NMR (100 MHz, TMS, DMSO- $\left.d_{6}\right): \delta(\mathrm{ppm}) ; 18.1$ (C-12), 20.9 (C-10), 55.2 (C-13), 56.6 (C-11), 77.2 (C-9), 87.4 (C-3), 109.1 (C-5), 119.9 (C-7), 137.4 (C-8), 159.4 (C-2), 162.2 (C-4), 169.7 (C-6). ESI+-MS: m/z 247.0960 $[\mathrm{M}+\mathrm{Na}]^{+}\left(\right.$calcd for $\left.\mathrm{C}_{12} \mathrm{H}_{16} \mathrm{O}_{4} \mathrm{Na}, 247.0941\right) \cdot[\alpha] \mathrm{D}^{25}+34.4(\mathrm{c}$ $0.08, \mathrm{MeOH})$.

\section{Results and Discussion}

Table 1 indicate that the number of fungal strains (688) we recovered from eight species of macroorganisms is in agreement with the results of previous investigations that marine invertebrates, in particular filter-feeding animals, host a large number of microorganisms (Friedrich et al., 2001; Lee et al., 2001; Piel, 2009; Bugni \& Ireland, 2004; Fenical, 1993; Kobayashi \& Ishibashi, 1993; Pietra, 1997). The three Didemnidae ascidian species we collected yielded a slightly smaller number of associated 
fungi than sponges. A similar result was obtained from a single specimen of marine alga, Sargassum sp. Two distinct collections of the ascidian Didemnum ligulum and of the sponge Axinella cf. corrugata were made. We have observed that the number of fungal strains associated with these animals varied in each collection (data not shown), but we cannot ascertain the reason why we observed such a variation in the number of strains isolated, in each case.

Table 1. Number of strains isolated from each marine macroorganism.

\begin{tabular}{llcc}
\hline & \multicolumn{1}{c}{ Macroorganism } & Strains & Total \\
\hline Ascidians & white Didemnidae & 55 & 227 \\
& Didemnum granulatum & 26 & \\
& Didemnum ligulum & $146^{*}$ & \\
\hline Sponges & Axinella cf. corrugata & $111^{*}$ & 410 \\
& Dragmacidon reticulata & 40 & \\
& Geodia corticostyllifera & 80 & \\
& Mycale angulosa & 179 & \\
\hline Alga & Sargassum sp. & 51 & 51 \\
\hline Total & & & 688 \\
\hline *Strains obtained from two distinct collections.
\end{tabular}

*Strains obtained from two distinct collections.

The number of fungal isolates recovered from each macroorganism depended on the inoculation method and growth media used for the isolation of strains. Figure 1 shows that the spread of diluted homogenates on Petri dishes yielded 144 strains, while the spread of marine organism fragments on Petri dishes led us to obtain 197 strains. The isolation of marine-derived fungi by simply inoculating $1 \mathrm{~cm}^{3}$ fragments of marine organisms on Petri dished yielded 347 strains. This last procedure enabled us to obtain pure strains faster than using the fragment or homogenate spread. The same procedure was used by Höller et al. (2000), who were able to isolate 681 strains of marine-derived fungi from sixteen species of marine sponges, while we isolated 410 strains from four species of marine sponges. A quite similar protocol was reported by Kjer et al. (2010) as very appropriate for the isolation of marine-derived fungal strains. Therefore, this method appears to be highly suitable for the isolation of marinederived fungal strains associated to marine organisms. We subsequently used only the deposition of marine macroorganism fragments on the agar of Petri dishes for the recovering of pure fungal strains.

When considering the culture media used for the isolation and purification of marine-derived fungal strains, we observed a large variation in the number of strains obtained, depending on the media used for such purpose (Figure 2), in agreement with Bredholt et al. (2008) for the isolation of Streptomycetes and Sangnoi et al. (2009) for the isolation of marine gliding bacteria. The use of artificial sea water (ASW) as a growth medium provided the smallest number of strains (seven). This result is not surprising when one considers that this is a selective and a nutritionally very depleted medium. Only strains which need almost no nutrients for growth will be isolated on ASW agar. Furthermore, such strains usually grow more slowly. Thus, it is possible that some strains we have not obtained in nutritionally depleted media may have been overlooked, because they were left to grow for only 28 days. Some fungal strains may require up to three months of incubation for growth, such as Penicillium tropicoides (Houbraken et al., 2010). The marine fungus Plectosporium oratosquillae, for example, requires 21 days to grow $15-16 \mathrm{~mm}$ in potatocarrot agar (Duc et al., 2009). In our experiments, other nutritionally depleted media, such as cellulose and Tubaki, yielded a considerable number of marine-derived fungi. Similar results were obtained by Menezes et al. (2010). These results confirmed the fact that the isolation of fungal strains from the marine environment is highly dependent on the media used for isolation (Bugni \& Ireland, 2004). When nutritionally richer media have been used, such as oat meal, potato and carrot, $2 \%$ malt and $3 \%$ malt, a much larger number of strains were obtained (Figure 2). Furthermore, 3\% malt is a medium free of complex fat mixtures, a suitable feature for obtaining crude extracts from microbial growth media. We observed that oat meal, potato-carrot and corn meal media yielded more lipid-rich extracts. Fremlin et al. (2009) and Kjer et al. (2010) also reported the advantages of using malt-based media for the isolation and growth of marine-derived fungal strains for the production of bioactive extracts. The use of different media is useful to enhance the isolation of taxonomically unrelated strains. For example, in the present investigation nine different media yielded 410 fungal strains from four marine sponge species, while Höller et al. (2000) obtained 681 strains from sixteen species of marine sponges using six different media. It is desirable to use media with drastically distinct composition for such purposes, but the growth of fungal strains must be adequately performed in each media. A careful choice of media and growth conditions must be considered depending on the purposes aiming the isolation of marine fungal strains.

In the case of isolation and growth of marinederived fungal strains, the effect of seawater concentration in the media is also significantly relevant, as showed by Bugni \& Ireland (2004), Yang et al. (2007) as well as by our previous investigations (Vita-Marques et al., 2008; Pimenta et al., 2010). In general, high sea water concentration inhibits rather than promotes the growth and secondary metabolites production.

The percentage of strains isolated which yielded bioactive crude extracts varied consistently between 20 and $35 \%$ for each growth medium (Table 2 and Figure 3 ). Interestingly, we did not observe any correlation between a particular medium feature, such as being nutritionally rich or depleted, and the isolation of strains which yielded 
bioactive crude extracts. For example, $34 \%$ of the strains isolated in Tubaki (a nutritionally depleted medium) gave active extracts, while over $29 \%$ of strains obtained in the nutrient rich corn meal medium produced active crude extracts (Figure 3 ). These results show that a considerable percentage of marine-derived microbial strains produce bioactive secondary metabolites, regardless of the media used for their isolation. Exception made to the strains isolated from the marine sponges Axinella cf. corrugata and Geodia corticostyllifera, and from the alga Sargassum sp., the majority of strains isolated from the remaining marine macroorganisms yielded cytotoxic rather than antibiotically active crude extracts. Among 435 extracts tested in cytotoxicity assays, $23 \%$ displayed moderate or potent cytotoxic activity (Table 3 and Figures 4 and 5). Additionally, strains yielded an almost comparable number of potently and moderately cytotoxic crude extracts, in all four cancer cell lines on which the extracts have been tested. Considering the antibiotic activity displayed by the crude extracts obtained from the marine fungal strains isolated, the largest number of extracts were active against Staphylococcus aureus, followed by extracts active against Streptococcus sanguinis and Streptococcus mutans (two strains), but only a small number of crude extracts displayed a significant activity in antimicrobial assays.

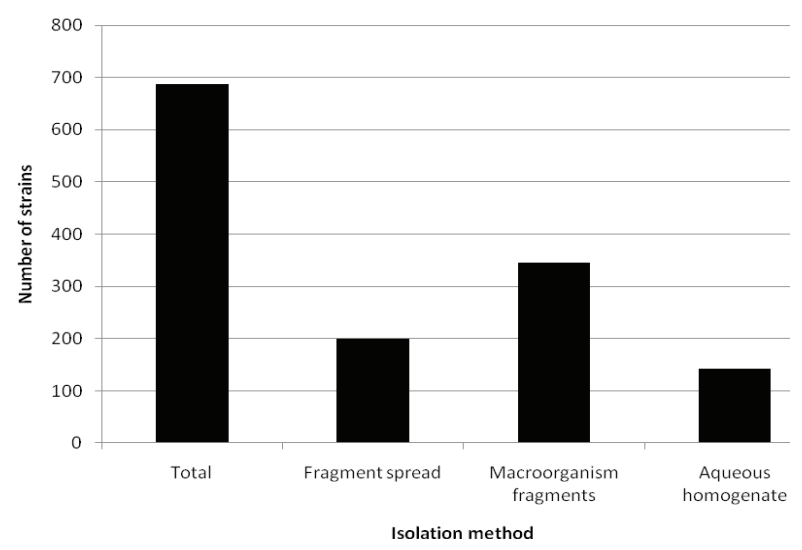

Figure 1. Number of strains isolated from marine macroorganisms using different inoculation methods.

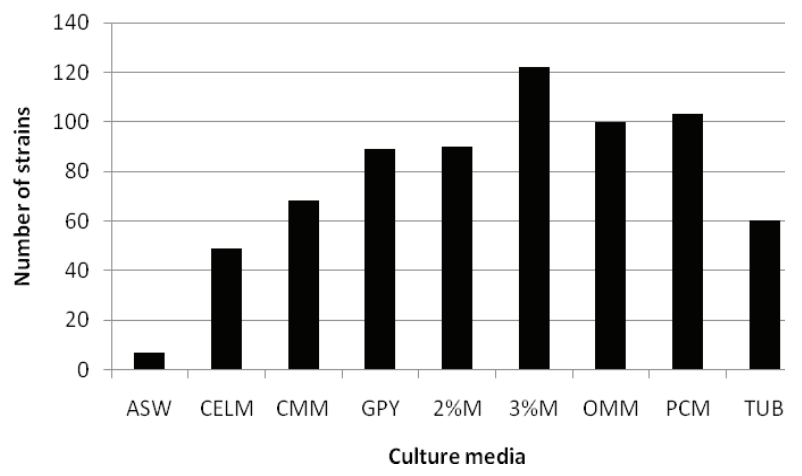

Figure 2. Number of marine-derived fungal strains isolated using different culture media. Growth media: see experimental section.

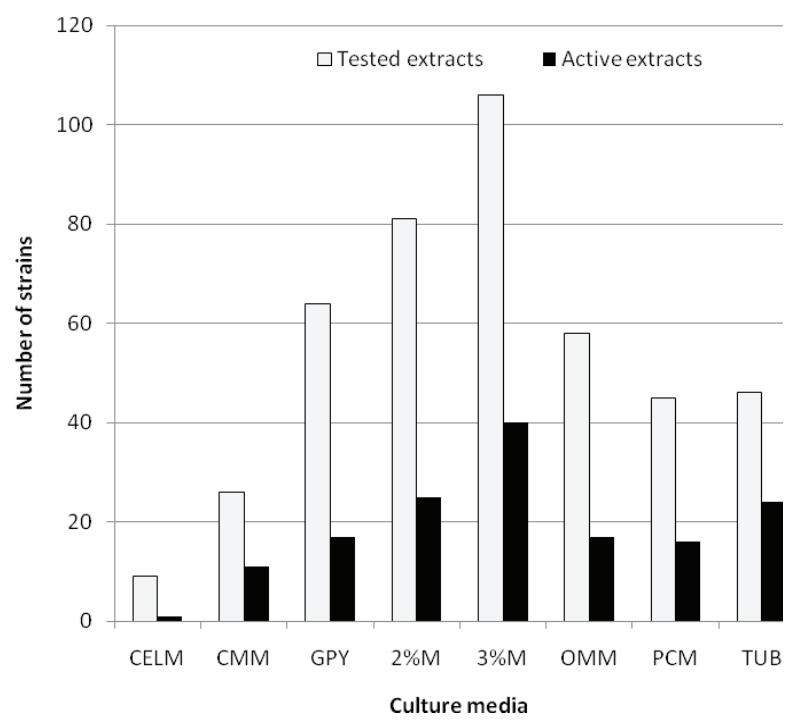

Figure 3. Tested fungal extracts and active fungal extracts per culture medium. See the experimental section for growth media abbreviations.

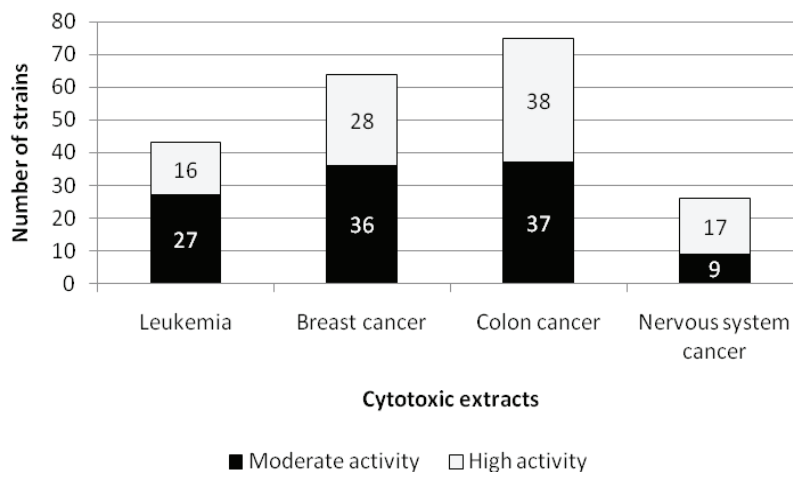

Figure 4. Cytotoxic activity of extracts obtained from marinederived fungi. Cancer cell lines: Leukemia (HL60 human cancer cells), Breast (MDA-MB435 human mammalian breast cancer cells), Colon (HCT8 human colon cancer cells), Nervous system cancer (CNS 295 cancer cells). Potency: moderate cytotoxic activity $=50 \%$ to $75 \%$ inhibition of cancer cell growth; high cytotoxic activity $=>75 \%$ inhibition of cancer cell growth.

The evaluation of methods used for the isolation of marine-derived fungal strains has been occasionally addressed. Höller et al. (2000) used a single procedure for the incubation of marine sponge fragments in Petri dishes, using six different media for the isolation of marine-derived fungi, and isolated 681 fungal strains from sixteen species of sponges, but did not mention the effect of distinct growth media on the number of strains recovered. Jensen et al. (2005) were able to obtain 6,425 actinomycetes strains from 288 marine sediment and marine macroorganism samples. Actinomycetes were obtained from $77 \%$ of all samples inoculated in growth media. The authors showed the significant influence of isolation methods on the recovery of actinomycete strains and indicated the importance on 
Table 2. Number of strains isolated from marine macroorganisms which yielded bioactive crude extracts*

\begin{tabular}{lccc}
\hline \multicolumn{1}{c}{ Macroorganism } & $\begin{array}{c}\text { \# strains which yielded crude } \\
\text { extracts }\end{array}$ & \# tested crude extracts & $\begin{array}{c}\text { \# strains which yielded active } \\
\text { crude extracts }\end{array}$ \\
\hline White Didemnum & 55 & 40 & 13 \\
D. granulatum & 26 & 26 & 5 \\
D. ligulum & 146 & 44 & 18 \\
Axinella cf. corrugata & 111 & 67 & 15 \\
D. reticulata & 40 & 40 & 26 \\
G. corticostilifera & 80 & 56 & 32 \\
M. angulosa & 179 & 127 & 37 \\
Sargassum sp. & 51 & 35 & 5 \\
Total & 688 & 435 & 151 \\
\hline
\end{tabular}

*Only extracts obtained in $>20 \mathrm{mg}$ were subjected to bioassays.

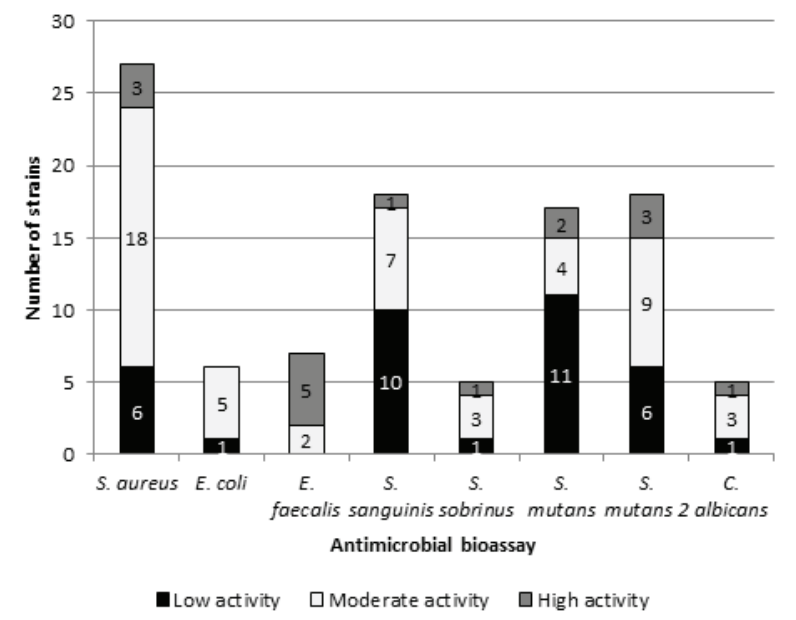

Figure 5. Antimicrobial activity of extracts obtained from marine-derived fungi. $\mathrm{MIC}=$ minimal inhibitory concentration Potency: low antimicrobial activity $=\mathrm{MIC} \geq 250 \mu \mathrm{g} / \mathrm{mL}$; moderate antimicrobial activity $=\mathrm{MIC}$ at $125 \mu \mathrm{g} / \mathrm{mL}$; high antimicrobial activity $=$ MIC $\leq 67.5 \mu \mathrm{g} / \mathrm{mL}$.

the improvement of culture methods for the isolation and growth of obligate marine actinomycetes. Romanenko et al. (2008) used diluted homogenates of the mollusk Anadara broughtoni for the isolation of 149 strains of marine bacteria. Only eight of the 149 strains isolated displayed antibiotic activity on human pathogenic bacteria. Bredholt et al. (2008) used four different media for the isolation of 3200 actinomycetes from Norwegian marine sediments. Extracts of all strains were obtained in three different growth media, and tested against Micrococcus luteus and Candida albicans. The percentage of active extracts varied depending on the site of sediment collection, ranging from $13 \%$ to $58 \%$ of strains which produced active extracts. The importance of media used for extracts production was not discussed. Hong et al. (2009) used eleven different media for the isolation of actinomycetes from mangrove samples, aiming to test crude extracts produced by these bacterial strains in antibiotic, cytotoxic and "biochemical" assays. However, the authors did not discuss any aspect related to the importance of media used for the isolation or growth of the strains obtained, or even related to the activity of the extracts obtained. A single growth medium was used by Dharmaraj \& Sumantha (2009) for the isolation of 94 streptomycetes strains from four species of marine sponges. More than $28 \%$ of the strains isolated produced extracts that displayed broad antibacterial activities. Antibacterial activity was observed for extracts of 58 of the strains isolated, while 63 of the strains isolated produced antifungal extracts. Zhang et al. (2009) reported the isolation of 43 fungal strains obtained from eight species of marine algae and three species of marine invertebrates using a single growth medium. Over $84 \%$ of the strains isolated displayed antibiotic activity against at least one human microbial pathogen, and over $23 \%$ inhibited at least four of such pathogenic strains. Sangnoi et al. (2009) also used a single medium for the isolation of 84 strains of marine gliding bacteria from biofilms, invertebrates and algae. Among the strains isolated, 27 were selected based on their morphological features for growth in four different media for the production of extracts. After growth, extracts obtained from these media were tested for cytotoxic activity against four cancer cell lines. The results obtained showed that strains grew faster in a casitone, malt extract plus yeast extract based medium than in a baker's yeast paste medium, or in a peptone plus yeast extract based medium, or even in skim milk plus yeast extract based medium, and produced the largest number of cytotoxic extracts in the same medium as well.

The above mentioned studies indicate the importance of a careful choice on the conditions used for strains isolation and growth for secondary metabolites production, in order to obtain a significant number of strains which produce bioactive compounds.

In the present investigation, a few strains were 
selected based on their bioactive and chemical (HPLC/ $\mathrm{UV} / \mathrm{MS}$ ) profiles, as well as considering the generation of suitable amounts of extracts from the culture media, aiming at the isolation of pure secondary metabolites. These strains were also submitted to taxonomic identification.

Norliquexanthone (1), also known as 1,3,6trihydroxy-8-methyl-9H-xanthen-9-one, was isolated from the fungus $P$. raistrikii obtained from the sponge Axinella cf. corrugata and identified by analysis of spectroscopic data along with comparison with literature data (Sundholm, 1978). The structure and absolute stereochemistry of $(S)$ 8-methoxy-3,5-dimethylisochroman-6-ol (2), isolated from $P$. steckii obtained from an alga belonging to the genus Sargassum, could be established by analysis of spectroscopic data and also by comparison with literature data (Lai et al., 1990; Masuma et al., 1994; He et al., 2004; Kerti et al., 2007). A Penicillium sp. strain DG(M3)6'C, isolated from the ascidian Didemnum granulatum, yielded 13-desoxy-phomenone (4), identified by analysis of spectroscopic data and comparison with literature data (Tirilly et al., 1983). Roridin A (5) was isolated from Trichoderma sp. obtained from the sponge $M$. angulosa and also identified by analysis of spectroscopic data and comparison with literature data (Steinmetz et al., 2008). All known compounds isolated were reportedly bioactive as antimicrobial and/or cytotoxic agents.

The fungal strain $\mathrm{Ma}(\mathrm{G}) \mathrm{K}$, obtained from the sponge $M$. angulosa and identified as $P$. paxilli, gave an extract which was cytotoxic against MDA-MB435 (human mammalian cancer cells), HCT8 (human colon), CNS 295 (central nervous system cancer cells) and HL60 (leukemia) cells. Fractionation of this crude extract yielded three 2-pyrones, belonging to the class of pyrenocines, of which two were known (6 and 7), and one was a new natural product (8). Pyrenocines B (6) and A (7) were first isolated from Pyrenochaeta terrestris and identified by spectroscopic and X-ray diffraction analysis (Sato et al., 1979; Sato et al., 1981). Compounds 6 and 7 isolated by us from $P$. paxilli growth medium presented ${ }^{1} \mathrm{H}$ and ${ }^{13} \mathrm{C}$ chemical shifts virtually identical to those reported in the literature (Sato et al., 1981).

The new compound $\mathbf{8}$ presented a $[\mathrm{M}+\mathrm{Na}]^{+}$ion at $\mathrm{m} / \mathrm{z}$ 247.0960, corresponding to the formula $\mathrm{C}_{12} \mathrm{H}_{16} \mathrm{O}_{4}$. Typical pyrenocines ${ }^{1} \mathrm{H}$ NMR signals observed at $\delta 3.83$ (s, OMe-11), 2.28 (s, Me-12) and 5.61 (s, H-3), as well as ${ }^{13} \mathrm{C}$ signals at $\delta 159.2(\mathrm{C}-2), 87.4(\mathrm{C}-3), 162.2(\mathrm{C}-4), 109.1$ (C-5), 169.7 (C-6), 56.6 (C-11) and 18.1 (C-12) were in agreement with literature values for the 2-pyrone moiety in 8. The presence of a 1-(E)-3-methoxybut-1-enyl chain in 8 could be ascertained by analysis of COSY and HMBC spectra. In the COSY spectrum, the terminal methyl group at $\delta 1.20$ showed a vicinal correlation to the oxymethine proton at $\delta 3.8(\mathrm{~m}, \mathrm{H}-9)$, which was sequentially coupled to the vinylic proton at $\delta 5.81(\mathrm{dd}, 7.2$ and $16 \mathrm{~Hz}, \mathrm{H}-8)$, which in turn was coupled to another vinylic proton at $\delta$ $6.20(\mathrm{~d}, 16 \mathrm{~Hz}, \mathrm{H}-7)$. In the HMBC spectrum, one of the two methoxyl groups $\left(\delta_{\mathrm{H}} 3.2 ; \delta_{\mathrm{C}} 55.2\right)$ showed a long range coupling to the carbon at $\delta 77.1$ (C-9), thus establishing its connection to C-9. Finally, the vinylic protons at $\delta$ 5.81 and 6.20 showed long range couplings to the carbons C-4, C-5 and C-6, enabling us to completely establish the planar structure of 8 as $(E)-4-m e t h o x y-5-(3-m e t h o x y b u t-$ 1-enyl)-6-methyl-2H-pyran-2-one. Although $\mathbf{8}$ is optically active, with $[\alpha] \mathrm{D}^{25}+34.4(\mathrm{c} 0.08, \mathrm{MeOH})$, it did not present a Cotton effect in circular dichroism analysis. Due to the small amount of $\mathbf{8}$ available, we did not attempt to establish its absolute configuration. On this basis, 8 was identified as a new natural product for which we propose the name pyrenocin J. Pyrenocines have been reported as being cytotoxic and antibiotic (Sparace et al., 1987; Amagata et al., 1998; Rukachaisirikul et al., 2007).

In conclusion, in the present investigation we<smiles>Cc1cc(O)cc2oc3cc(O)cc(O)c3c(=O)c12</smiles>

1

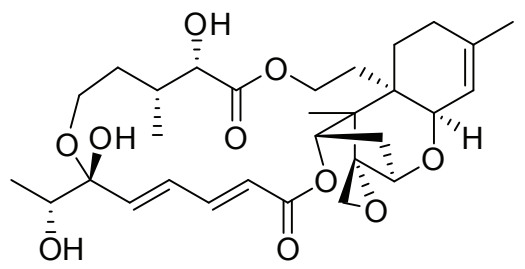

5<smiles>COc1cc(O)c(C)c2c1CO[C@H](C)C2</smiles>

2<smiles>COc1cc(=O)oc(C)c1C(=O)CC(C)O</smiles>

6<smiles>COc1cc2c(c(O)c1C)COC(C)C2</smiles>

3<smiles>C/C=C/C(=O)c1c(OC)cc(=O)oc1C</smiles>

7<smiles>CC(=O)C12OC1C1(C)C(=CC2=O)CCC(O)C1C</smiles>

4<smiles></smiles>

8 
observed that adequate procedures for the isolation, growth and secondary metabolite production by marinederived fungi should be carefully evaluated. Deposition of marine macroorganisms fragments on Petri dishes appears to be the most suitable inoculation method for the isolation of marine-derived fungal strains. While nutrientrich media are suitable for the isolation of a large number of marine-derived fungal strains that produce bioactive extracts, nutrient-depleted media may yield taxonomically distinct strains which also present active extracts. Growth conditions must be adjusted depending on the media used for the isolation, and secondary metabolites production marine-derived fungi. The use of $3 \%$ malt medium proved to be the most suitable for the isolation of a significant number of bioactive secondary metabolite producing fungal strains from marine macroorganisms. The use of distinct isolation conditions enabled us to obtain a wide variety of marine-derived fungal strains, which yielded several active secondary metabolites after fractionation of selected bioactive crude extracts. Among the compounds isolated, pyrenocine $\mathrm{J}(\mathbf{8})$ is a new natural product isolated from the marine-derived fungus $P$. paxilli obtained from the sponge $M$. angulosa.

\section{Acknowledgments}

The authors thank Alvaro E. Migotto, past principal of the Centro de Biologia Marinha, for logistic and technical support, as well as Raymond J. Andersen and David E. Williams (University of British Columbia, Vancouver, Canada) for collecting spectroscopic data of compound 5. Funding was provided by BIOTA/ BIOprospecTA FAPESP grants (2005/60175-2 and 2010/50190-2). MHK, SR, CX, MCM, MZV, EFP, RPM, CMM, LFCC and VMB thank FAPESP for scholarships. $\mathrm{SR}, \mathrm{EC}$. and BV thank CNPq for scholarships.

\section{References}

Amagata T, Minoura K, Numata A 1998. Cytotoxic metabolites produced by a fungal strain from a Sargassum Alga. $J$ Antibiot 51: 432-434.

Bredholt H, Fjærvik E, Johnsen G, Zotchev SB 2008. Actinomycetes from sediments in the Trondheim Fjord, Norway: diversity and biological activity. Mar Drugs 6: $12-24$.

Bugni TS, Ireland CM 2004. Marine-derived fungi - a chemically and biologically diverse group. Nat Prod Rep 21: 143163.

Cox RH, Hernandez O, Dorner JW, Cole RJ, Fennell DI 1979. New isochroman mycotoxin isolated from Penicilliumsteckii. J Agr Food Chem 27: 999-1001.

Deshmukh SK 2003. The maintenance and preservation of keratinophilic fungi and related dermatophytes. Mycoses 46: 203-207.
Dharmaraj S, Sumantha A 2009. Bioactive potential of Streptomyces associated with marine sponges. World $J$ Microbiol Biotechnol 25: 1971-1979.

Duc PM, Hatai K, Kurat, O, Tensha K, Yoshitaka U, Yaguchi T, Udagawa SI 2009. Fungal infection of mantis shrimp (Oratosquilla oratoria) caused by two anamorphic fungi found in Japan. Mycopathologia 167: 229-247.

Fenical W 1993. Chemical studies of marine bacteria - developing a new resource. Chem Rev 93: 1673-1683.

Fremlin LJ, Piggott AM, Lacey E, Capon RJ 2009. Cottoquinazoline A and cotteslosins A and B, metabolites from an australian marine-derived strain of Aspergillus versicolor. J Nat Prod 72: 666-670.

Friedrich AB, Fischer I, Proksch P, Hacker J, Hentschel U 2001. Temporal variation of the microbial community associated with the mediterranean sponge Aplysina aerophoba. FEMS Microbiol Ecol 38: 105-113.

Gallagher KA, Fenical W, Jensen PR 2010. Hybrid isoprenoid secondary metabolite production in terrestrial and marine actinomycetes. Curr Opin Biotechnol 21: 794-800.

He G, Matsuura H, Takushi T, Kawano S, Yoshiwara T 2004. A new antifungal metabolite from Penicillium expansum. $J$ Nat Prod 67: 1084-1087.

Hernandez ILC, Godinho MJL, Magalhães ABS, Ferreira AG, Berlinck RGS 2000. $N$-acetyl- $\gamma$-hydroxyvaline lactone, an unusual amino acid derivative from a marine streptomycete, J Nat Prod 63: 664-665.

Hernandez ILC, Macedo ML, Berlinck RGS, Ferreira AG, Godinho MJL 2004 . Dipeptide metabolites from the marine derived bacterium Streptomyces acrymicini. J Braz Chem Soc 15: 441-444.

Höller U, Wright AD, Matthee GF, König GM, Draeger S, Aust HJ, Schulz B 2000. Fungi from marine sponges: diversity, biological activity and secondary metabolites. Mycol Res 104: 1354-1365.

Hong K, Gao AH, Xie QY, Gao H, Zhuang L, Lin HP, Yu HP, Li J, Yao XS, Goodfellow M, Ruan JS 2009. Actinomycetes for marine drug discovery isolated from mangrove soils and plants in China. Mar Drugs 7: 24-44.

Houbraken JAMP, Frisvad JC, Samson RA 2010. Taxonomy of Penicillium citrinum and related species. Fungal Divers 44: 117-133.

Hughes CC, Fenical W 2010. Antibacterials from the sea. Chem Eur J 16: 12512-12525.

Jensen PR, Fenical W 1994. Strategies for the discovery of secondary metabolites from marine bacteria - ecological perspectives. Annu Rev Microbiol 48: 559-584.

Jensen PR, Gontang E, Mafnas C, Mincer TJ, Fenical W 2005. Culturable marine actinomycete diversity from tropical Pacific Ocean sediments. Environ Microbiol 7: 10391048 .

Kelecom A 2002. Secondary metabolites from marine microorganisms. An Acad Bras Cienc 74: 151-170.

Kerti G, Kurtán T, Tünde-Zita I, Kövér KE, Sólyom S, Pescitelli G, Fujioka N, Berova N, Antus S 2007. Enantioselective 
synthesis of 3-methylisochromans and determination of their absolute configurations by circular dichroism. Eur $J$ Org Chem 2007: 296-305.

Kjer J, Debbab A, Aly AH, Proksch P 2010. Methods for isolation of marine-derived endophytic fungi and their bioactive secondary products. Nature Protocols 5, 479-490.

Kobayashi J, Ishibashi M 1993. Bioactive metabolites of symbiotic marine microorganisms. Chem Rev 93: 17531769.

Kossuga MH, Lira SP, McHugh S, Torres YR, Lima BA, Gonçalves R, Veloso K, Ferreira AG, Rocha RM, Berlinck RGS 2009. Antibacterial modified diketopiperazines from two ascidians of the genus Didemnum. J Braz Chem Soc 20: 704-711.

Lai S, Shizuri Y, Yamamura S, Kawai K, Terada Y, Furukawa H 1990. New metabolites of 2 hybrid strain ME-0004 and ME-0005 derived from Penicillium-citreo-viride B IFO 6200 and 4692. Chem. Lett.: 589-592.

Lee YK, Lee JH, Lee HK 2001. Microbial symbiosis in marine sponges. J Microbiol 39: 254-264.

Lira SP, Vita-Marques AM, Seleghim MHR, Bugni TS, LaBarbera D, Sette LD, Sponchiado SRP, Irleland CM, Berlinck RGS 2006. New destruxins from the marine-derived fungus Beauveria felina. J Antibiot 59: 553-563.

Masuma R, Tabata N, Tomoda H, Haneda K, Iwai Y, Omura $\mathrm{S}$ 1994. Arohynapene-A and arohynapene-B, new anticoccidial agents produced by Penicillium sp. taxonomy, fermentation and structure elucidation. $J$ Antibiot 47: 46-53.

Menezes CB, Bonugli-Santos RC, Miqueletto PB, Passarini MRZ, Silva CHD, Justo MR, Leal RR, Fantinatti-Garboggini F, Oliveira VM, Berlinck RGS, Sette LD 2010. Microbial diversity associated with algae, ascidians and sponges from the north coast of São Paulo state, Brazil. Microbiol Res 165: 466-482.

Newel SY 1976. Mangrove fungi: the sucession in the mycoflora of red mangrove (Rhizophora mangle L.). In Jones EBG (Ed.). Recent advances in aquatic mycology. UK: Paul Elek Scientific Books, p. 51-91.

Newman DJ, Hill RT 2006. New drugs from marine microbes: the tide is turning. $J$ Ind Microbiol Biot 33: 539-544.

Piel J 2009. Metabolites from symbiotic bacteria. Nat Prod Rep 26: 338-362.

Pietra F 1997. Secondary metabolites from marine microorganisms: bacteria, protozoa, algae and fungi. Achievements and prospects. Nat Prod Rep 14: 453464.

Pimenta EF, Vita-Marques AM, Tininis A, Seleghim MHR, Sette LD, Veloso K, Ferreira AG, Williams DE, Patrick BO, Dalisay DS, Andersen RJ, Berlinck RGS 2010. Use of experimental design for the optimization of the production of new secondary metabolites by two species of Penicillium. J Nat Prod 73: 1821-1832.

Rateb ME, Ebel R 2011. Secondary metabolites of fungi from marine habitats. Nat Prod Rep 28: 290-344.
Romanenko LA, Uchino M, Kalinovskaya NI, Mikhailova VV. 2008. Isolation, phylogenetic analysis and screening of marine mollusc-associated bacteria for antimicrobial, hemolytic and surface activities. Microbiol Res 163: 633-644.

Rukachaisirikul, V, Kaeobamrung, J, Panwiriyarat, W, Saitai, P, Sukpondma, Y, Phongpaichit, S, Sakayaro, J 2007. A New pyrone derivative from the endophytic fungus Penicillium paxilli. Chem Pharm Bull 55: 1383-1384.

Saleem M, Ali MS, Hussain S, Jabbar A, Ashraf M, Lee YS 2007. Marine natural products of fungal origin. Nat Prod Rep 24: 1142-1152.

Sangnoi Y, Srisukchayakul P, Arunpairojana V, Kanjana-Opas A 2009. Diversity of marine gliding bacteria in Thailand and their cytotoxicity. Electronic J Biotechnol 12: DOI: 10.2225/vol12-issue3-fulltext-13.

Sato H, Konoma K, Sakamura S, Furusaki A, Matsumoto T, Matsuzaki T 1981. X-ray Crystal structure of pyrenocine A, a phytotoxin from Pyrenochaeta terrestris. Agric Biol Chem 45: 795-797.

Sato H, Konoma K, Sakamura S 1979. Phytotoxins produced by onion pink root fungus, Pyrenochaeta terrestris. Agric Biol Chem 43: 2409-2411.

Seleghim MHR, Lira SP, Kossuga MH, Batista T, Berlinck RGS, Hajdu E, Muricy G, Rocha RM, Nascimento GF, Silva M, Pimenta EF, Thiemann OH, Oliva G, Cavalcanti BC, Pessoa C, Moraes MO, Hajdu E, Peixinho S, Rocha RM 2007. Antibiotic, cytotoxic and enzyme inhibitory activity of crude extracts from Brazilian marine invertebrates. Rev Bras Farmacogn 17: 287-318.

Sparace, SA, Reeleder, RD, Khanizadeh, S 1987. Antibiotic activity of the pyrenocines. Can J Microbiol 33: 327330.

Steinmetz WE, Robustelli P, Edens E, Heineman D 2008. Structure and conformational dynamics of trichothecene mycotoxins. J Nat Prod 71: 589-594.

Sundholm EG 1978. Chemical studies on lichens. 34. Total syntheses of lichen xanthones-revision of structures. Tetrahedron 34: 577-586.

Tirilly Y, Kloosternan J, Sipma G, Kettenes-Van den Bosch JJ 1983. A fungitoxic sesquiterpene from Hansfordia pulvinata. Phytochemistry 22: 2082-2083.

Yang LH, Miao L, Lee OO, Li X, Xiong H, Pang KL, Vrijmoed L, Qian PY 2007 Effect of culture conditions on antifouling compound production of a sponge-associated fungus. Appl Microbiol Biotechnol 74: 1221-1231.

Vita-Marques AM, Lira SP, Berlinck RGS, Seleghim MHR, Sponchiado SRP, Tauk-Tornisielo SM, Barata M, Pessoa C, Moraes MO, Coelho B, Nascimento GGF, Souza AO, Minarini PRR, Silva CL, Silva M, Pimenta EF, Thiemann O, Passarini MRZ, Sette LD 2008. A multi-screening approach for marine-derived fungal metabolites and the isolation of cyclodepsipeptides from Beauveria felina. Quim Nova 31: 1099-1103.

Zhang Y, Mu J, Feng Y, Kang Y, Zhang J, Gu PJ, Wang Y, Ma LF, 
Zhu YH 2009. Broad-spectrum antimicrobial epiphytic and endophytic fungi from marine organisms: isolation, bioassay and taxonomy. Mar Drugs 7: 97-112.

\section{*Correspondence}

Roberto G. S. Berlinck

Instituto de Química de São Carlos, Universidade de São Paulo

Caixa Postal 780, 13560-970, São Carlos-SP, Brazil

rgsberlinck@iqsc.usp.br

Tel: +55162739954

Fax: +55162739952 